ORNL/M--1503

DE91 016465

\title{
SAS2H INPUT AND ASSUMPTIONS FOR CASES COMPUTING ISOTOPIC ACTIVITIES FOR SEQUOYAH NUCLEAR PLANT
}

\author{
Principal Investigator:

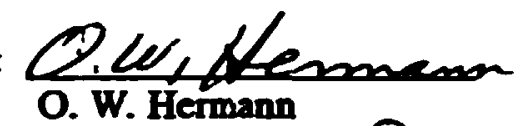 \\ Reviewer:

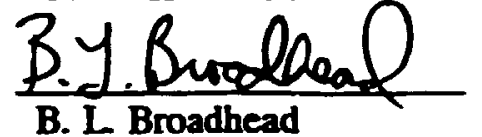 \\ Approved by: $\frac{C_{\text {end }} \text {. P. Pule }}{\text { C. Y. Parks, Supervisor }}$ \\ Computing and Telecommunications Division \\ Nuclear Engineering Applications Department \\ Oak Ridge National Laboratory \\ Oak Ridge, Tennessee
}

July 1991

NOTICE: This document contains information of a preliminary nature. It is subject to revision or correction and therefore does not represent a final report.

Work sponsored by the

Tennessee Valley Authority

under Contract No. ERD-91:1017

(TVA No. TV84400V)

MARTIN MARIETTA ENERGY SYSTEMS, INC.

managing the

Oak Ridge National Laboratory Oak Ridgc Y-12 Plant

Oak Ridge Gaseous Diffusion Plant Paducah Gaseous Diffusion Plant

for the

U.S. DEPARTMENT OF ENERGY

under contract DE-AC05-84OR21400 


\section{ACKNOWLEDGMENTS}

This work was initiated by R. L. Sanders of the Tennessee Valley Authority (TVA). The author appreciates the excellent response to supplying the reactor data necessany for this project by D. M. Brown and C. W. Burrell, also with TVA.

The author wishes to acknowledge other members of the Nuclear Engineering Applications Department staif of Oak Ridge National Laboratory: B. L. Broadhead for reviewing the computer cases, M. C. Brady for obtaining the electronic output, and C. V. Parks for advice and guidance. 


\section{ABSTRACT}

Sequoyah Nuclear Plant core activities, required in nuclear safety evaluations, were computed by the SAS2H analysis sequence and the GRIGEN-S code within the SCALE-4 system. 


\section{OBJECTTVE}

This report describes 's:- work performed to satisfy contract no. ERD-91-017 with the TVA The TVA requested technicai support regarding the computation of core activities to be assumed in a design basis loss-of-coolant accident (LOCA) for TVA's Sequoyah Nuclear Plant (SQN). Core activities for the required reactor parameters have been compicted using the SAS2H/ORIGEN-S analysis sequence in the SCALE-4 system.' The ORIGEN-S activity tables have been transmitted to R. L Sanders of TVA by floppy dists. Hard-copy printouts of all of the SAS2H and ORIGEN-S cases have also been provided to Mr. Sanders.

This report gives all of the sources of the input to the codes and states any significant assumptions used in the input.

\section{SOURCES OF THE CODE INPUT}

This section provides the references used to obtain the detailed problem description from which the code input data for SAS2H and ORIGEN-S were obtained.

The core fuel loading and assumed power history were given in the statement of work in the project contract. ${ }^{2}$ Assembly and pin oiesign dimensions and nominal coolant pressure were taken from Chapter 4 of the SQN Final Jafety Analysis Re;ort (FSAR) as supplied by ref. 3. The effective or average material-zone temperatures and the boron concentration in the coolant were specified in a special core parameter inpt: report for this project. The set of light element masses per assembly were computed from the masses per unit weight of uranium used in a recent decal heat project." The ut $\%{ }^{36} U$ was computed from the ${ }^{35} U$ enrichment in a formula used in other projects. ${ }^{5.7}$ The wt $\%{ }^{25} U$ was calculated consistent with the method used in a burnup credit project ${ }^{7}$ from the following formula: $w \%{ }^{34} U=0.007731\left(w_{1} \%{ }^{3 s} U\right)^{10037}$. Cross sections for 13 actinides, 181 fission products, and 5 light elements on the SCALE-4 burnup library (27BURNUPLIB; were updated with XSDRNPM-S derived fluxes on the 18 ORIGEN-S librarics produced by SAS2H. 


\section{CASES COMPUTED}

The names and purposes of the SAS2H/ORIGEN-S cases for which hard-copy printout is being provided to TVA are:

$$
\begin{aligned}
& \text { OWHSQ300 - 3.00 ut } \%{ }^{35} \text { U SAS2H case for libraries } \\
& \text { OWHSQ375 - } 3.75 \text { ut } \%{ }^{35} U \text { SAS2H case for libraries } \\
& \text { OWHSQ450 - } 4.50 \text { wt } \%{ }^{35} \text { U SAS2H case for libraries } \\
& \text { OWHSE300 - } 3.00 \text { wt } \%{ }^{35} U \text { ORIGEN-S case for activities } \\
& \text { OWHSE375 - } 3.75 \text { ut } \%{ }^{35} \text { U ORIGEN-S case for activities } \\
& \text { OWHSE450 - } 4.50 \text { wt } \%{ }^{25} \text { U ORIGEN-S case for activities } \\
& \text { OWHAB300 - } 3.00 \text { ut } \%{ }^{35} \text { U ORIGEN-S case for neutron absorptions } \\
& \text { OWHAB375 - 3.75 ut } \%{ }^{35} U \text { ORIGEN-S case for neutron absorptions } \\
& \text { OWHAB450 - } 4.50 \text { ut } \%{ }^{35} \text { U ORIGEN-S case for neutron absorptions }
\end{aligned}
$$

On the floppy disks given TVA, the files named S300CASE.OUT, S375CASE.OUT, and S450CASE.OUT contain output corresponding to the printout of OWHSE300, OWHSE375, and OWHSE450, respectively. The ORIGEN-S cases that computed neutron absorption fractions of nuclides were added to assist in explaining differences in SAS2H/ORIGEN-S and nonderletion code results.

The initial SAS2H and ORIGEN-S cases were reviewed and approved by R. L Sanders of TVA prior to completion of the analyses. The electronic output described and the hard-copy output for all cases have been transmitted to $R$. L. Sanders of TVA.

\section{SLMMARY}

Time-dependent core activities were computed by SAS2H/ORIGEN.S for Sequoyah Nuclear Plant Units 1 and 2. Hard-copy and electronic case printouts are being provided to $R$. L. Sanders of TVA under separate cover. The sources of essential code input are referenced, and the cases are identified in this report. The appendices include plots of time-dependent total activities, together with the activities for several important nuclides. An example of the job control language and input of one of the SAS2H cases (3.0 wt \% ${ }^{23 s} \mathrm{U}$ ) are alsc included in the Appendix. 


\section{REFERENCES}

1. SCALE: A Modular Code System for Performing Standardized Computer Anahyses for Licensing Evaluation, Vols. 1-3, NUREG/CR-0200, U.S. Nuclear Regulatory Commissicn [originally issued July 1980; reissued January 1982; Rev. 1 issued July 1982; Rev. 2 issued June 1983; Rev. 3 issued December 1984; Rev. 4 (draft) issued February 1990].

2. "Statement of Work for Calculation of Isotope Activities for Sequoyah Nuclear Plant (SQN)," Appendix A of Contract No. ERD-91-1017 between the Martin Marietta Energy Systeins, Inc., and the Tennessee Valley Authority, April 31, 1991.

3. Letter from P. G. Trudel, Tennessee Valley Authority, to Cecil Parks, Oak Ridge National Laboratory, "Sequoyah Nuclear Plant Units 1 and 2 - Information to Execute the ORIGEN Computer Codes" (received May 1991).

4. D. M. Brown, "Determination of Representative Core Parameters for ORNL Environmental Qualification (EQ) Calculation," File No. PFE-G97, RIMS No. L36 910515 801, Tennessec Valley Authority (May 1991).

5. O. W. Hermann, J. P. Renier, and C. V. Parks, Technical Support for a Proposed Decay Heat Guide Using SAS2H/ORJGEN-S Data, NUREG/CR-5625, ORNL/CSD-130, Martin Marictta Energy Systems, Inc., Oak Ridge Natl. Lab. (to be published).

6. S. P. Cerne, O. W. Hermann, and R. M. Westfall, Reactivity and Isotopic Composition of Spent PWR Fuel as a Function of Initial Enrichment, Bumup, and Cooling Time, ORNL/CSD/TM-244, Martin Marietta Energy Systems, Inc., Oak Ridge Natl. Lab. (October 1987).

7. O. W. Hermann. Data Compiled in Bumup Credit Isotope Validation Study, ORNLM-1425, Martin Marietta Energy Systems, Inc., Oak Ridge Natl. Lab. (April 1991). 
APPENDIX A

PLOTS OF SEQUOYAH NUCLEAR PLANT

FUEL ASSEMBLY ACTIVITIES 


\section{SEQUGYAH FUEL ACTIVITY - 3.0 WT \% U235}

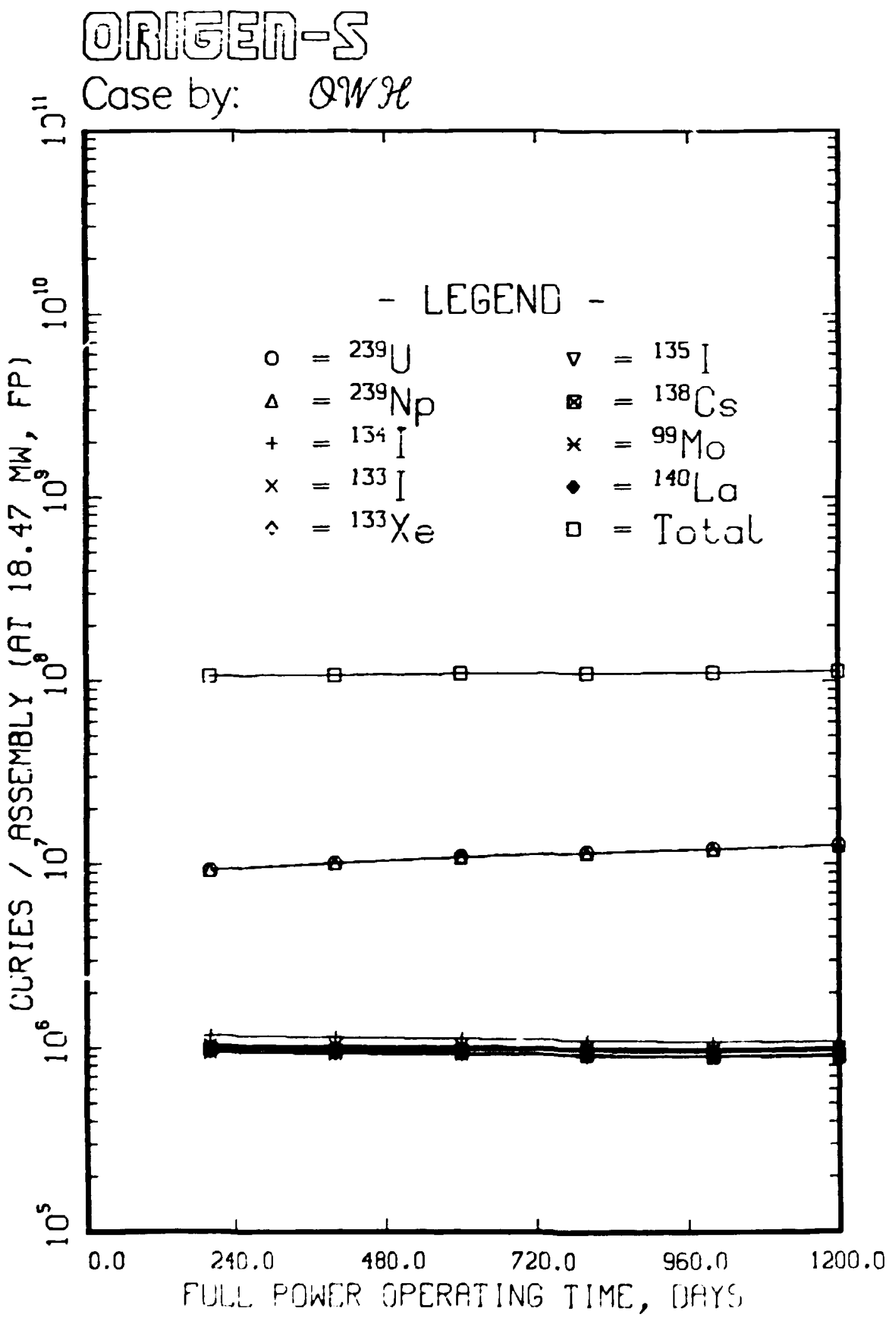




\section{SEQUOYAH FUEL ACTIVITY - 3..5 WT \% U235}

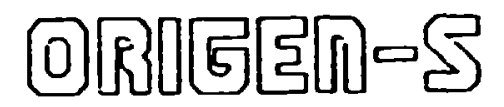

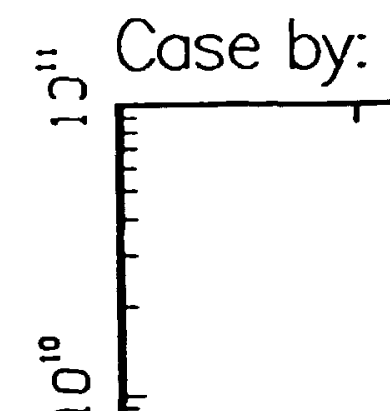

QWH

ơ

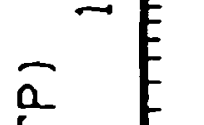

L

z
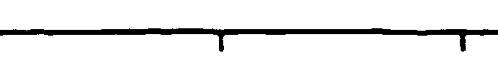


\section{SEQUOYAH FUEL ACTIVITY - 4.50 WT \% U235}



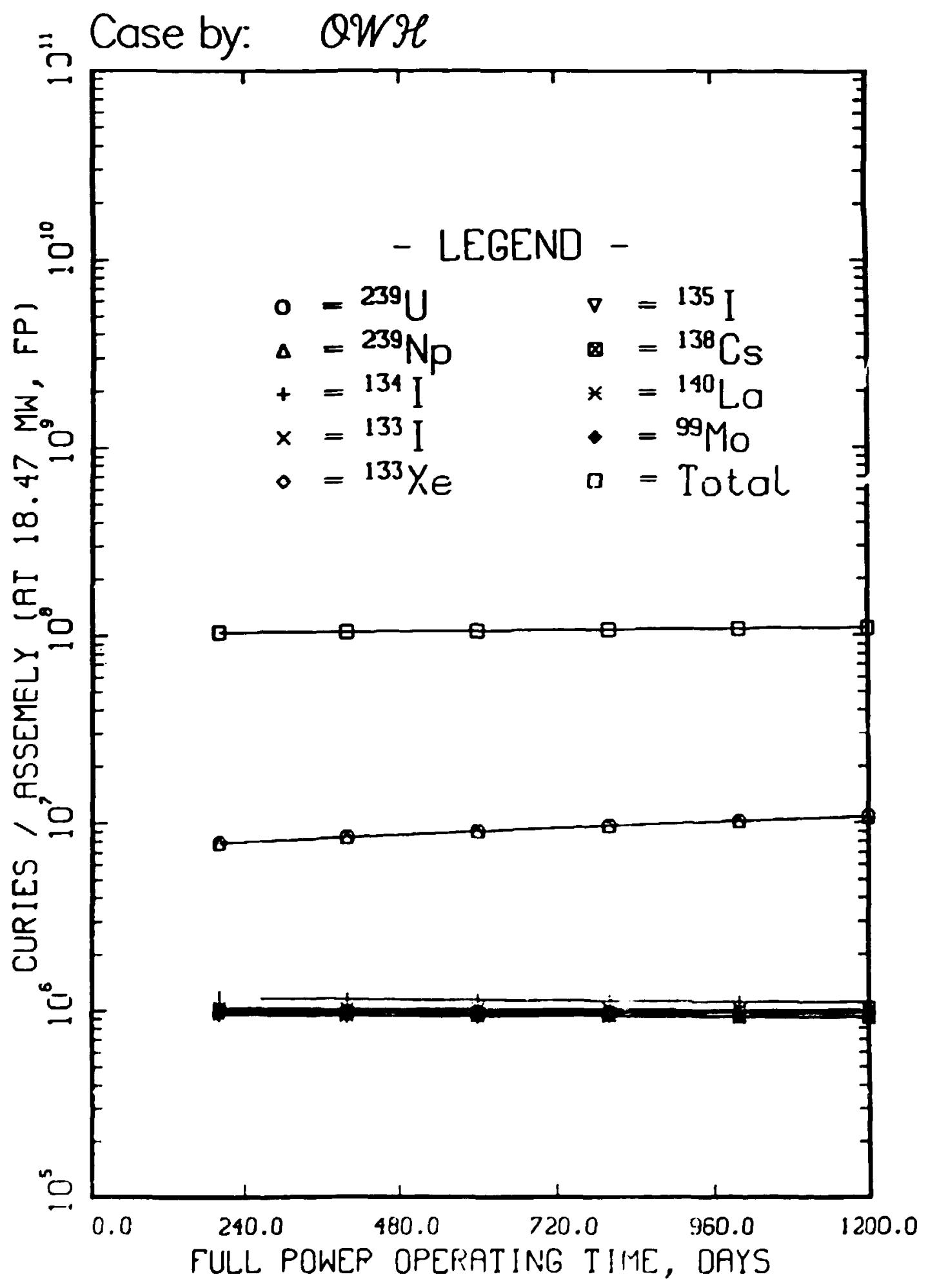


APPENDIX B

EXAMPLE OF JCL AND INPUT TO SASZH CASE (3.0 WT \% ${ }^{25} U$ ) 


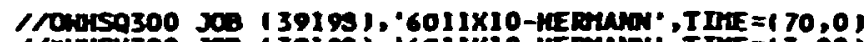

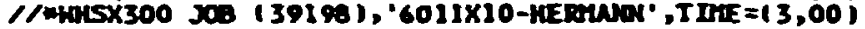

$1 / 1$

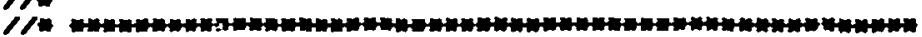

$1 / 1$

$1 / \div$

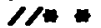

$1 \%$

$1 /$.

$1 / 1$

1iㅡ

1/4

$1 / 1$

$1 /$ in

17 .

슨

$1 / 7$

18 .

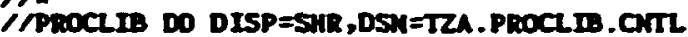

$1 /$ in

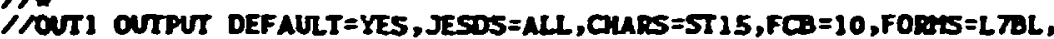
$1 /$ DEST $=2 \times 10 A$, COPIES $=1$

/NUII OUTPUT DEFAULT=XES, JESOS=AL,

$1 /$ DEST $=$ DOHO5 5, COPIES $=1$

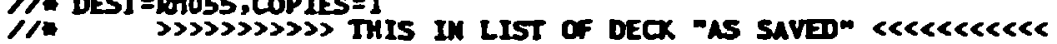

$1 / 1$

1/. SAVDa on OAM.TVA.squ

N/minIM LIMES $=98$

Ninith CLASS=STANoBx

YSPDA EXEC SPDASCR

/ SYSPRINT of SYSOUT $=$

ASYSIK Do

T.OHH 39198 . Sow1FT90

T. OnA 39198 . 5041FT70

T.0.1139198.50N1FT72

T. OWH39198. SONIFT74

T. OHH 39198 . SOM1FT55

10

T.CWH39198.SONIFT

Hoot Exec poolscR

SYSPRIN Do sysour $=$

1 SYEIN Do

OAN LB3004TP. PHR1 T 33

OAH. LB 300HTP. PHRI 736

ONH . LB $300 N T P$. PHR I T 35

OHA . LB 30ONT P. PHR I T 36

ONA. LB 300NTP. PHRI T 37

OAM . LB 3004TP. PHR 1 T 38

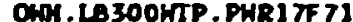

10

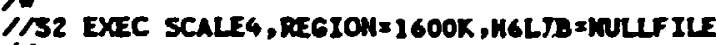

$1 / 6$

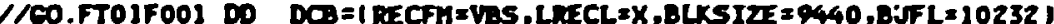

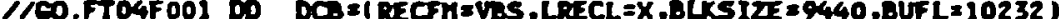

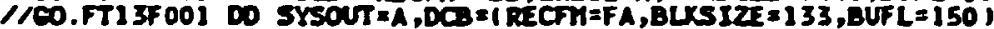

(N00.FTi $6 F 00\}$ Do SPACExiTR, (200,801)

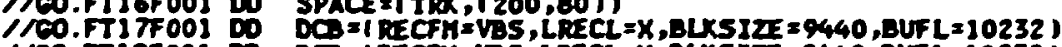

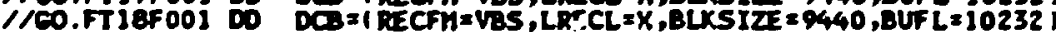

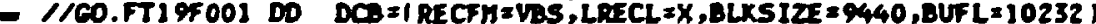

I/CO.FTgOF 001 Do SPACE a TRK, 110,011 , UnITISPOA.

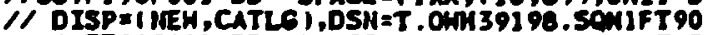

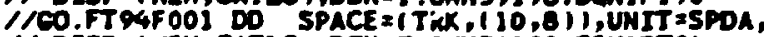

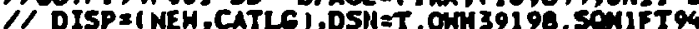

/CO.FT32F 00\} DO UNIT =SYSOA,SPACE = (TRK, $(30,5))$

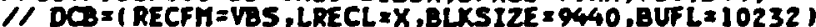

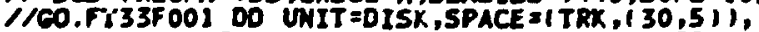

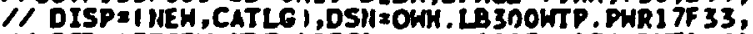

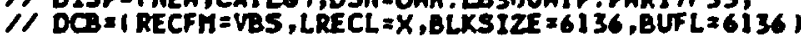

- /CO.FT36F001 00 UNIT=0ISK,SPACE $=1$ TRK, 130,511 ,

- $/$ DISP INEH, CATLEI, DSN

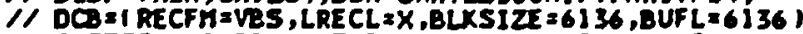

//CO.FT 35F001 OD UNIT $=0 I S K$, SPACE $=1$ TRK, $(30,51)$,

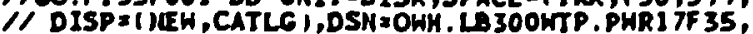




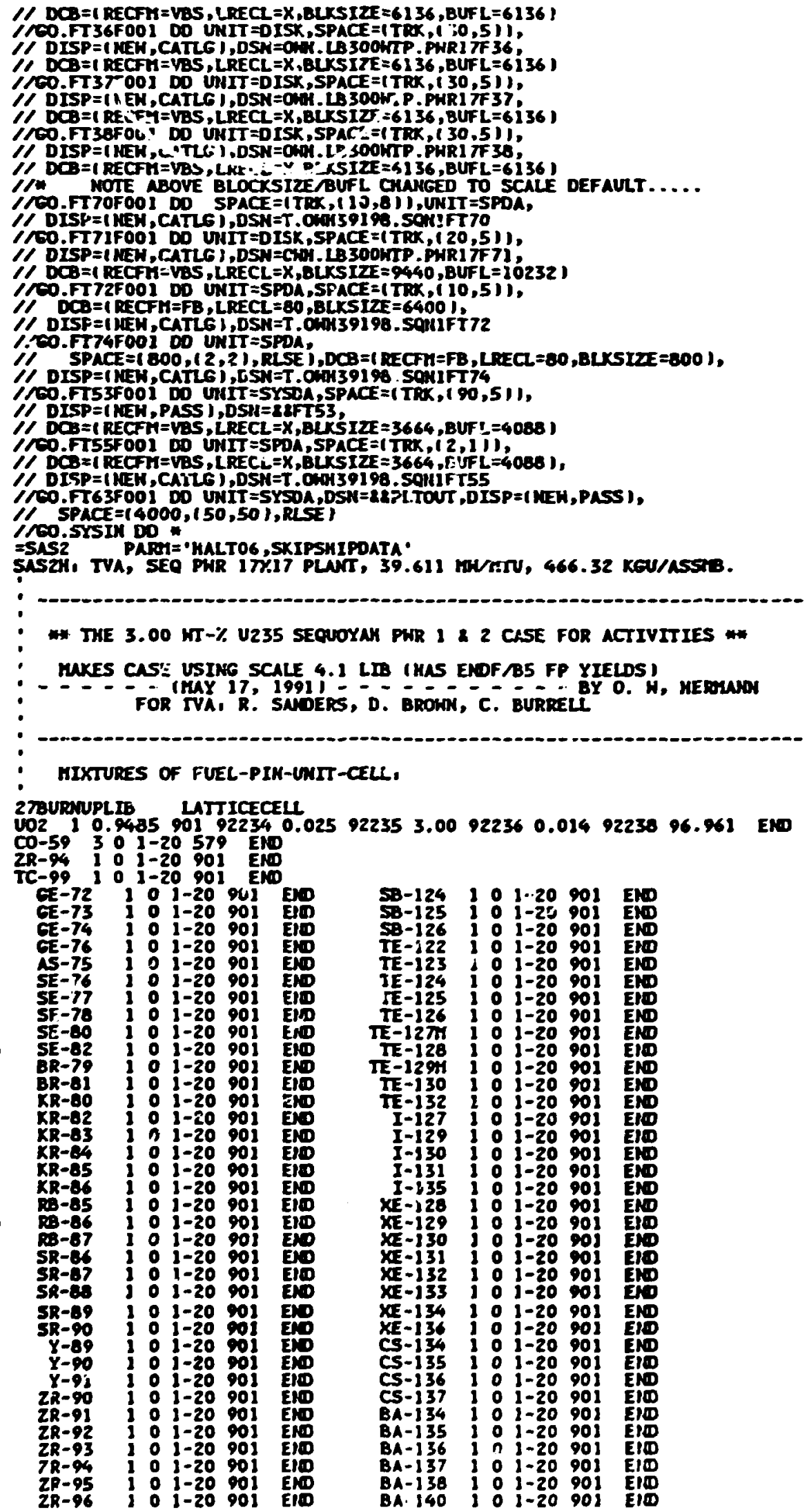




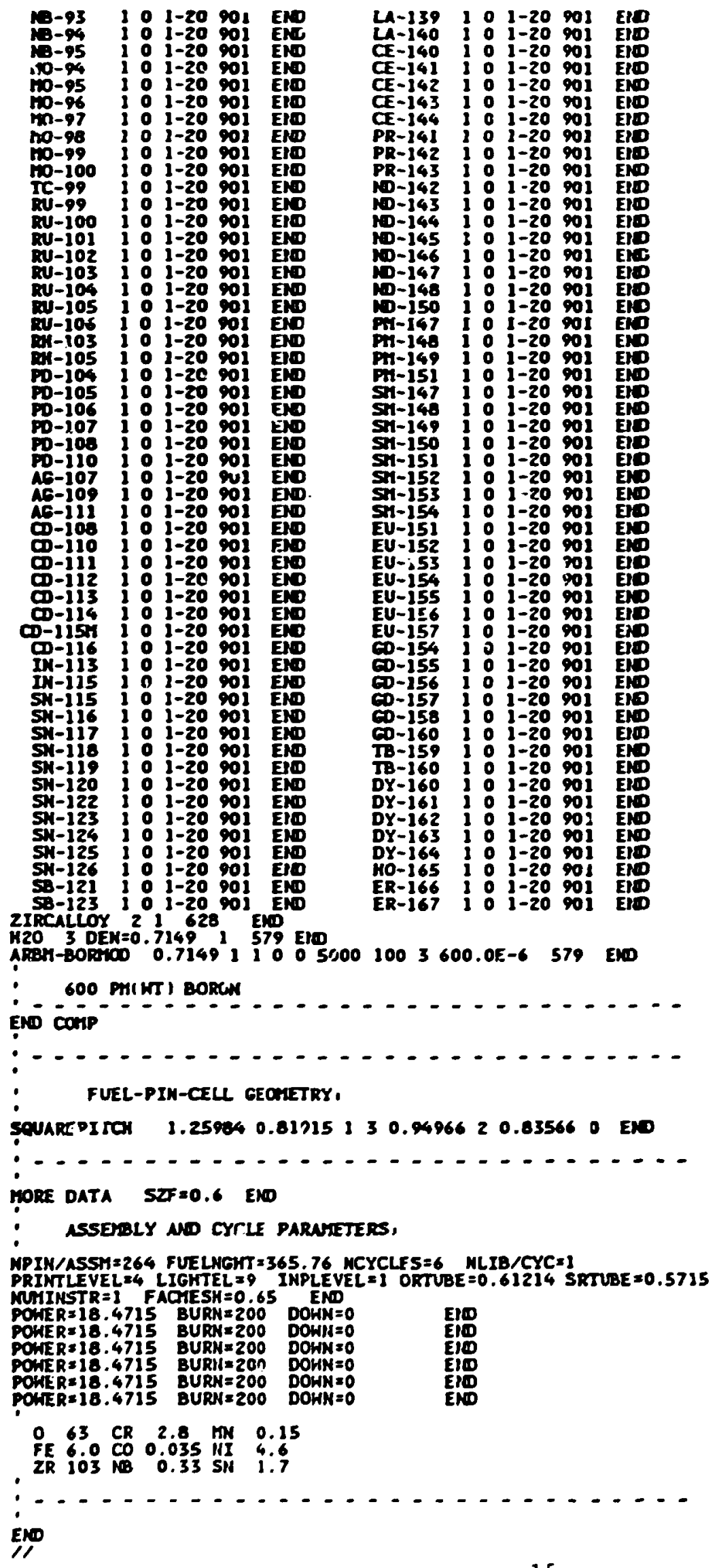

